\title{
Creación poética y competencia literaria: propuestas didácticas
}

Poetic creation and literary competence: didactic proposals

\author{
MARÍA ROSAL NADALES \\ Universidad de Córdoba \\ España
}

\begin{abstract}
Resumen. Se muestran diversas propuestas didácticas basadas en la escritura creativa en el aula, con la intención de fomentar la animación a la lectura y a la escritura, con el consiguiente incremento de la competencia literaria. Los poemas propuestos son textos contemporáneos escritos por mujeres y nos interesan especialmente para observar la construcción de sujetos poéticos inéditos y la revisión de los modelos patriarcales. Intentamos con ello aportar a los estudiantes textos que favorezcan la discusión sobre los valores ideológicos y estéticos de la literatura.
\end{abstract}

Palabras clave: Creación poética; competencia literaria; revisión; modelos patriarcales; mujer.

\begin{abstract}
Several didactic proposals are presented which are based on the creative writing in the classroom, the main goal is encourage both reading and writing, and through this improvise students literary competence. The suggested poems are contemporary texts written by women and their interest lies in the building up of new poetical subjects and the revision of patriarchal models. We try to provide the students with texts that encourage the discussion of ideological and aesthetic values of literature.
\end{abstract}

Keywords: Poetic creation, literary competence, review; patriarchal models; women. 


\section{EI taller de creación literaria y el desarrollo de competencias.}

Partimos de la concepción del aula como un espacio de comunicación, un canal adecuado para el desarrollo de las competencias comunicativas. En este sentido nos parece importante la planificación y el desarrollo de propuestas de intervención didáctica que fomenten dichas competencias. Para ello planteamos una propuesta centrada en la idea de la escritura creativa en el aula como recurso lúdico que pueda fomentar la animación a la lectura y a la escritura, con el consiguiente incremento de la competencia literaria definida, en el sentido en el que afirma Sánchez Corral: "Es en el contexto de los estudios generativistas sobre el lenguaje literario donde surge la noción de competencia literaria, formulada ya en 1965 por M. Bierwisch como «una específica capacidad humana que posibilita tanto la producción de estructuras poéticas cuanto la comprensión de sus efectos» (2003: 305).

Trabajamos con el texto literario por parecernos el más idóneo para que se produzca "la acción reguladora del discurso", lo que constituye "un excelente medio para que cada persona pueda elaborar, de manera coherente, su autoestima y su autoconcepto", tal y como señala Sánchez Corral (2003: 295) y ya mostrara Bajtin: "Los más productivos en este sentido son los géneros literarios y los menos favorecedores aquellos discursos que requieren formas muy estandarizadas y convergentes, por ejemplo, los documentos burocráticos y oficiales" (Sánchez Corral, 2003: 295). Planteamos, pues, una propuesta eminentemente práctica, por lo que hemos centrado nuestra atención en textos poéticos aglutinados bajo el tema común del retrato y del autorretrato.

La construcción de la identidad posee enorme valor en todas las etapas de la vida, muy especialmente en la adolescencia y primera juventud, cuando el sujeto va conformando el propio autoconcepto, a través de la experiencia y los datos que le suministra la manifestación de las percepciones de los demás. Y es en esta relación con "los otros" y consigo mismo donde dialoga y se autoconstruye, ensaya y rechaza, elige identidad e identidades. En este proceso, el desarrollo de la competencia comunicativa, "determina de manera decisiva la construcción del sujeto" (Sánchez Corral, 2003: 293). 
Son muchos los elementos que reflejan las señas de identidad de un grupo o persona, muy especialmente entre los jóvenes: su ropa, el culto al cuerpo, la moda, su música, las series de televisión, la publicidad o las marcas... Por ello, proponer a los estudiantes textos cuyo principal argumento es el retrato, nos parece interesante para cualquiera de las etapas educativas, ya sea primaria, secundaria o primeros años de Facultad. La propuesta que aportamos corresponde a la experimentación con estudiantes de la Titulación de Maestro, con la intención de plantear actividades de intervención didáctica lúdicas y creativas que puedan servir de estímulo para el diseño de futuras actividades en sus respectivas aulas, con el convencimiento de que el taller ${ }^{1}$ literario constituye un impulso significativo para la educación literaria.

Por otra parte, nos parecen destinatarios adecuados puesto que, por edad cronológica, se sitúan en la primera juventud, atareados en la construcción de su propia identidad. De esta manera, pueden conocer de primera mano la experimentación de una experiencia de taller, su secuenciación didáctica y participar en ella como sujetos creadores que, además, reflexionan sobre las posibilidades didácticas de la experiencia creativa. El trabajo se desarrolla en la asignatura "Lenguaje creativo en el aula" para estudiantes de segundo curso de la Titulación de Maestro.

\section{El autorretrato en poesía. Propuesta de intervención didáctica.}

\subsection{Objetivos.}

La lectura de textos literarios se plantea como una actividad práctica cargada de enorme potencial significativo. Si a ello unimos la propuesta de creación poética, el aula se perfila como un laboratorio experimental que favorece el desarrollo de las competencias lingüísticas y literarias.

\footnotetext{
${ }^{1}$ Amando López Valero nos aporta ideas fundamentales sobre la importancia del trabajo en el taller de literatura para la formación literaria. Cf. obras anotadas en bibliografía.
} 
El objetivo central de la didáctica de la literatura no puede ser otro que el de propiciar la adquisición y el desarrollo de la competencia literaria, entendida, claro está, no como una propiedad inmanente a la literalidad del texto, sino como una actividad discursiva que realiza el sujeto durante la recepción estética. (Sánchez Corral, 2003: 321).

Por lo que, si "el discurso literario interviene de manera decisiva en la construcción de la identidad del sujeto" y la literatura "se erige como un discurso necesario en la sociedad actual", parece imprescindible plantear en el aula "situaciones comunicativas, específicamente literarias, de manera que los alumnos no se vean privados de las virtualidades significativas y expresivas que comportan los textos artísticos" (Sánchez Corral, 2003: 321). Son varios los objetivos propuestos en este sentido:

- Formar lectores y lectoras competentes, capaces de interpretar y valorar textos poéticos.

- Practicar la lectura expresiva.

- Desmitificar la lectura poética como un acercamiento "difícil" a la hermenéutica textual.

- Desvelar los contenidos sexistas presentes o denunciados en los poemas, dentro del marco ideológico y social en el que se inscriben.

Porque entendemos que la lectura provoca "una experiencia no solo estética, sino también axiológica" (Servén, 2004: 70), proponemos la necesidad de leer bajo sospecha, indagando lo que los textos dicen y lo que ocultan, lo dado y lo creado, según Bajtin. Por ello, hemos propuesto textos contemporáneos escritos por mujeres. Se trata de hacer explícitos tanto los modelos de mujer, presentes en los discursos patriarcales como en los discursos subversivos, que dialogan con éstos, porque "la literatura, que no es solo un sistema de valores estéticos sino, además, una cristalización de mitos sociales, es un conjunto de textos que se producen al arrimo de un discurso dominante: el discurso patriarcal”. (Servén, 2004: 70).

- Valorar el patrimonio cultural y literario. 
- Detectar cómo los textos dialogan entre sí.

- Escribir textos poéticos a partir de consignas dadas.

- Fomentar una actitud positiva ante la creación poética, de manera que los estudiantes puedan diseñar actividades creativas en sus aulas.

- Concebir la creación literaria como espacio de juego y de libertad.

- Entender la fase de corrección como espacio riguroso de revisión y recreación.

Este objetivo dialoga con el anterior, pues si bien entendemos que la persona que escribe debe hacerlo desde la libertad y el atrevimiento (respetando, eso sí, la coerción de la consigna), sin embargo, a la hora de corregir, debemos situarnos en el espacio de búsqueda de la coherencia y de la aplicación rigurosa de los conocimientos técnicos sobre composición, estructura, métrica, retórica...

- Utilizar los recursos de la red y la biblioteca para investigar sobre documentos literarios y pictóricos que enriquezcan el tema del retrato, como motivo cultural y estético.

\subsection{Contenidos}

- El retrato y el autorretrato: la prosopografía y la etopeya.

- La máscara autobiográfica y el monólogo dramático.

- El tono. La ironía. El retrato irónico.

- La construcción de la voz.

- Imágenes de mujer: Modelo subversivo versus modelo patriarcal.

- Las herramientas de la poesía: Métrica y retórica.

- Poemas propuestos para el comentario y como modelo textual para la escritura.

1. Posible autorretrato. (Silvia Ugidos, Las pruebas del delito, 1997).

2. Cuando una tiene sangre de ramera. (Carmen Jodra, Las moras agraces, 1999).

3. Desde el espejo. (Rosa Díaz. Gata mamá, 2003). 
4. Poema de escarnio y maldecir. (Silvia Ugidos, Las pruebas del delito, 1997).

\subsection{Metodología.}

Al proponer una metodología práctica, activa y participativa, pretendemos fomentar en los estudiantes una actitud crítica que les ayude a leer bajo sospecha los textos literarios, no solo desde una perspectiva estética, sino desde presupuestos ideológicos, al entenderlos como documentos históricos que encierran visiones del mundo y de las personas y que, con harta frecuencia, perpetuán estereotipos de género.

Se trata de una enseñanza que pretende la construcción del aprendizaje y la postulación de modelos que permitan a los estudiantes diseñar en sus aulas actividades que fomenten la adquisición y elaboración de información de manera autónoma.

El discurso literario [...] resulta ser un instrumento privilegiado del que dispone el individuo para instaurar la identidad de su propio YO y para descubrirse a sí mismo como sujeto, gracias a las posibilidades de significación que le brindan los textos. (Sánchez Corral, 2003: 299).

Aún así, insistimos en desmitificar el concepto de poesía confesional, por lo que, a la hora de elaborar las consignas, pediremos que inventen autobiografías ficticias como si fueran personales, o bien que mezclen trufadas "verdades literarias" con verdades biográficas. Perseguimos con ello que, de manera práctica, entiendan el sujeto poético como construcción textual.

Secuenciación:

1. Lectura individual del texto. Cada estudiante debe leer los poemas y tratar de responder a unas cuestiones para el posterior debate. En este sentido, realizamos dos tipos de actividades:

- Comentario de cada poema.

- Comentario comparado de dos o más poemas

2. Lectura en voz alta, insistiendo en la entonación cómplice con el tono y el sentido del texto. 
3. Comentario en grupo de cada poema.

- Cada vez que comentamos un poema nuevo lo relacionamos con el anterior, en cuanto a lo que dice y a cómo lo dice y, sobre todo, analizamos las imágenes y la ideología que proyecta.

- Señalamos en qué difieren y qué valores reacentúan. En definitiva-siguiendo a Bajtin-, cómo dialogan.

4. Composición bajo consigna de un nuevo texto.

5. Lectura en voz alta de sus textos y comentario.

Es fundamental crear un clima de confianza, tanto entre compañeros y compañeras como con la profesora, lo que debe facilitar la autoconfianza que les permita participar activamente en la actividad de creación de textos, aprovechando todo su potencial lúdico y creativo.

No cabe la menor duda de que, cuando el maestro o el profesor les ofrecen a sus alumnos situaciones comunicativas de naturaleza literaria, les están entregando no solamente los enunciados placenteros y lúdicos de los textos, sino que también les están entregando el proceso mismo de la enunciación: el ser dueños de la enunciación, bien como enunciadores, bien como enunciatarios, es uno de los mayores placeres que procura el dominio del discurso. (Sánchez Corral, 2003: 304).

A la hora de seleccionar los textos, hemos tenido en cuenta los valores literarios, ideológicos y de comunicación que ofrecen estos poemas, así como el sentido del humor y la ironía, que les aportan mayor seducción para la lectura individual y el comentario en grupo. Hemos preferido obras de mujeres poetas de hoy, por las voces novedosas que aportan, en cuanto al uso de la ironía para construir su propia identidad, como respuesta a los modelos reductores propuestos por el patriarcado.

\subsection{Actividades}

Con frecuencia, los modelos académicos para la enseñanza-aprendizaje de la literatura se han basado más en la transmisión de verdades canónicas sobre el conocimiento literario, sin más compromiso por parte de los estudiantes que el de memorizar y repetir 
oportunamente nombres de autores, obras, rasgos estilísticos ajenos a sus intereses, a veces adobados con lecturas de textos propuestos para un comentario que se convertía, en no pocas ocasiones, en un catálogo de figuras retóricas, en un modo de salir del paso en el examen, olvidando el placer de la lectura y de la elaboración creativa de textos. También en este contexto contienden los talleres literarios, que buscan, ante todo, conectar con la experiencia lectora de los estudiantes y fomentar la escritura creativa, lo que no quiere decir que, a pesar de sus buenas intenciones, muchas veces no se hayan realizado de manera poco sistemática en el aula y sin diseñar claramente sus objetivos y secuenciación.

En los años setenta, sin embargo, irrumpirán en este campo otro tipo de actividades de escritura que parecía corresponderse con la difusión de nuevos objetivos de acceso activo al placer literario, tanto en su recepción como en su emisión, a través de la desacralización de la obra literaria. [...] a menudo bajo la forma de talleres literarios, y muy masivamente en la escuela primaria, a partir de la divulgación de la obra de G. Rodari, tomaron el relevo de la tradicional redacción escolar. (Colomer, 1991: 25).

Las actividades que planteamos se pueden clasificar en varios tipos:

1. Actividades de lectura. Comenzamos con una lectura personal, silenciosa, para pasar a una lectura en voz alta, compartida.

2. Análisis de textos:

- Señalar las ideas principales, estructura semántica y métrica.

- Comentar las figuras retóricas en relación con la intención del texto. Indicar si en el retrato predomina la prosopografía o la etopeya. Señalar las metáforas, palabras clave, tono, ironía. Analizar la creación de la voz desde el punto de vista ideológico: sumisa, acorde con la tradición, revisionista, subversiva...

3. Escribir un poema bajo consigna.

4. Lectura de sus textos. Comentario personal ante el grupo clase. Aportaciones de los compañeros y compañeras. 
5. Autocorrección. Una vez oídos los comentarios del grupo clase y de la profesora, el estudiante debe revisar su poema, atendiendo también de manera importante a lo que le dicten sus propias apreciaciones. En la clase siguiente puede leer el texto revisado. Algunas pautas para la autocorrección:

- Leer el texto en voz alta, a solas, varias veces, y observar si encuentran versos, palabras o expresiones que disuenen.

- Releer el comienzo del poema y escribir, al menos, otro comienzo alternativo que el autor considere más significativo y con mayor potencial expresivo.

- Observar los dos últimos versos y reflexionar sobre si aportan o no una conclusión convincente al texto, desde el punto de vista semántico y estético. Si es así, deben explicar por qué y si no es así, deben escribir otro final.

- Perseguir y eliminar los adjetivos sobrantes, especialmente los antepuestos.

- Revisar los signos de puntuación, teniendo en cuenta el sentido del poema. Es conveniente volverlo a leer en voz alta para "oír" el texto.

6. Actividades de documentación. En internet o en libros de consulta, principalmente en antologías de poesía contemporánea, pueden encontrar información biobibliográfica sobre la obra de estas poetas, así como leer más poemas². Pueden exponer un comentario sobre la obra de las autoras y aportar otros poemas que les hayan interesado.

Veamos, a continuación, el desarrollo de las actividades propuestas.

\section{Poema 1: Posible autorretrato ${ }^{3}$. Silvia Ugidos.}

- ¿Qué modelo de mujer ofrece el poema?

\footnotetext{
2 Pueden encontrar antologías que recogen una amplia nómina de mujeres poetas en Benegas, N. (1997) Ellas tienen la palabra. Madrid: Hiperión; y Rosal Nadales, M. (2006) Con voz propia. Estudio y antología comentada de la poesía escrita por mujeres (1970-2005). Sevilla: Renacimiento.

3 En el anexo incluimos los poemas analizados.
} 
- ¿Qué intención tiene el adjetivo "posible" en el título?

- Describe el tono del poema.

- Señala los rasgos coloquiales presentes en el texto. ¿Qué valores aportan a la caracterización del sujeto poético?

- Señala las metáforas y comenta el valor estilístico y simbólico que aportan.

- ¿Qué poema de un autor muy conocido funciona como intertexto?

Silvia Ugidos (1972) comienza a publicar en la década de los noventa. El poema ofrece una manifiesta actitud subversiva del sujeto poético, conjugado con un leguaje coloquial, que le proporciona frescura a la vez que requiere un lector cómplice, contemporáneo. Además, el tono irónico facilita a la autora una útil herramienta para conjurar la ira $^{4}$ contra los modelos de mujer impuestos por el patriarcado. Sus versos dialogan con varios referentes culturales en la conclusión paradójica del verso final: ("soy, en el buen sentido de la palabra, 'mala'), remedo inteligente y burlón de la respuesta con la que el feminismo contestaba a la ideología patriarcal: "Las chicas buenas van al cielo... y las mala a todas partes". Por otro lado, también remiten a otro referente culto: el retrato con el que Antonio Machado se perfilaba en 1906. Aunque, eso sí, hay diferencias sustanciales, las que proporciona el adjetivo "posible" ya desde el título. De modo que, si el retrato de Machado se presentaba de una pieza, trazado con mano firme, el de Ugidos es vacilante y fragmentario, contradictorio, revisionista y subversivo, acorde con el momento histórico posmoderno.

La identidad presente, construida, se impone sobre la identidad pasada, o propuesta, a partir del verbo final del poema, donde "soy" nos remite mediante la antítesis al "quise ser" de las dos primeras estrofas. El sujeto lírico, que participa de las reglas del juego y

4 Muestras significativas del uso de la ironía en las poetas contemporáneas pueden leerse en Rosal Nadales, M. (2009). "Nuevas identidades femeninas: La ironía al servicio de la autoafirmación", en Lengua, Literatura y Género, X Simposio Internacional, 2007. Baeza: Universidad de Jaén, SEDLL, pp. 679-696. 
conoce el modelo de mujer requerido, manifiesta de esta manera su incapacidad y su determinación para no actuar conforme al perfil prediseñado, por lo que autoconstruye, como puede, su propio yo, con su fallos y contradicciones, pero personal. Renuncia así a la aprobación social, en favor de su propia coherencia interna, a la vez que reclama su derecho a la revisión y la autoconstrucción.

\section{Poema 2: Cuando una tiene sangre de ramera. Carmen Jodra.}

- ¿Cuál es la idea principal del poema?

- ¿Qué modelo de mujer nos presenta?

- Comenta las metáforas, así como el valor estilístico y simbólico que aportan.

- Señala la estructura métrica. ¿Con qué formas métricas de la tradición dialoga?

- Comentario comparado de los poemas 1 y 2

- Comenta qué rasgos reacentúa la voz del sujeto poético creado por Carmen Jodra en este poema, respecto a la voz lírica del poema de Ugidos.

- Comenta las antítesis. ¿Crees que se están oponiendo dos visiones antagónicas del mundo? ¿Por qué?

- Redacta unas líneas en las que se delimite el modelo de mujer propuesto en cada poema.

Carmen Jodra (1980) tuvo un gran éxito al obtener, con Las moras agraces, el premio Hiperión de poesía en 1999. Este poema, sustentado en la ironía y la antítesis, nos resulta interesante para su comentario por su carácter subversivo y provocador, que busca la complicidad receptora de lectores y lectoras de finales del siglo XX. La subversión está presente en todos los planos, tanto en el del significado, como en la forma. Si bien, por una parte, el sujeto poético rechaza los perfiles de la feminidad heredada ("escuchar los consejos e integrarse en la masa"), por otra, interpela los postulados de la ideología 
patriarcal a través de la ironía: "sangre de ramera", "la virtud aburre / a quien ha hecho del vicio todo un arte". De la misma manera, en el plano formal encontramos un correlato revisionista aplicado a la estructura métrica, pues, aunque parte de formas métricas canónicas como el soneto, es capaz de fracturarlas en una postura que, acorde con el posmodernismo de fin de siglo, reescribe el patrón clásico de cuartetos o serventesios para rimar los versos de cada estrofa con los de la siguiente ${ }^{5}$.

La subversión se hace notar en versos como: "Brutal desprecio hacia la mayoría" y la autoafirmación del yo en el verso 11: “ya tiene, y hace, y es, lo que prefiere”. Es un sujeto poético femenino que habita en los márgenes y ahí quiere seguir: "inclinación al mal", "sangre de ramera", lo que la lleva a definirse como mujer libre, capaz de elegir, tan alejada del modelo patriarcal.

Analizamos pues, la construcción de voces de mujeres a finales del XX y principios del XXI, que "dialogan”, según el concepto bajtiniano, con otras voces del pasado reciente. Son voces que se construyen desde la revisión y la subversión. Si bien en los poemas anteriores se contraponen dos modelos discursivos enfrentados desde el siglo XIX, el ángel del hogar frente a la mujer fatal, estos arquetipos femeninos, al ser contemplados desde la parodia y la ironía en el poema de Ugidos, y desde la autoafirmación y el rechazo a los modelos reduccionistas, en el caso de Jodra, se convierten en sujetos líricos tremendamente provocadores y contemporáneos, insertos en una sentimentalidad posmoderna, que participa de la ideología feminista, en lo que tiene que ver con la revisión de modelos.

Así, de la misma manera que el poema de Ugidos "dialoga" con el de A. Machado, el más reciente de Carmen Jodra parece interpelar directamente al de su contemporánea y presenta un avance significativo en la postura ideológica, pues si bien Ugidos se construía en la duda, entre lo que debe ser y lo que es, en Jodra el avance es muy significativo, pues

5 El esquema métrico fractura las formas canónicas, con trece endecasílabos y un pie quebrado: el heptasílabo del verso noveno, así como la particular distribución de las rimas: 11A 11B 11C 11D 11A 11B 11C 11D 7c 11D 11E 11C 11D 11E. 
diseña un sujeto poético que se autoafirma contra los postulados patriarcales, sin ninguna vacilación.

\section{Poema 3: Desde el espejo. Rosa Díaz.}

- ¿Cuál crees que es la intención del texto?

- ¿Qué simboliza el espejo?

- ¿Por qué la autora solo cita a mujeres?

- Si escribes un poema, tomando como modelo éste, podrías encontrar características identificadoras en hombres y mujeres de tu familia o solo en un género. Explica por qué.

El poema de Rosa Díaz (1946) presenta un sujeto poético que se autoconstruye a partir de un recorrido por la rama femenina de su árbol genealógico. Estaríamos hablando de la matriherencia, concepto que dialoga con el de matrofobia ${ }^{6}$, ambos presentes en el poema, pues el sujeto poético no solo se reconoce en el espejo de la madre, sino en el de toda una genealogía de mujeres que configuran su rostro y sus anhelos, sus fobias: "Envejezco como mamá y en fin, en el espejo, pongo el aire".

Es bastante frecuente, en poetas contemporáneas, que matriherencia y matrofobia se complementen, de manera que, junto a posturas que rechazan lo heredado, encontramos la valoración de saberes trasmitidos entre mujeres, así como la revisión del cuerpo de la madre, tanto aceptado como rechazado o incluso como evocación del propio: "Invitación" (Cristina Peri Rossi, Evohé, 1971); “Confirmación“(Concha García, Otra ley, 1987).

\section{Poema 4: Poema de escarnio y maldecir. Silvia Ugidos.}

6 Nos hemos referido al tratamiento de las relaciones madre-hija en Rosal Nadales, M. (2009). Matriherencia y matrofobia en la literatura española contemporánea. En Arriaga M. (dir.) Escrituras del sur, (pp. 297-312). Sevilla: Arcibel Editores. 
- Tras leer el título, explica una hipótesis del contenido del poema. ¿Qué expectativas de lectura genera? ¿Se cumplen al leer el texto?

- ¿Qué opinas del sujeto lírico que da voz a los versos? ¿Cuál es su postura vital?

- Comenta el tono del poema.

- ¿Por qué podemos afirmar que el retrato que presenta este texto es mordaz?

- ¿Qué valor estilístico posee la introducción del estilo directo en el poema?

- Al hablar de las "virtudes" del joven, el sujeto poético habla con una voz bivocal, que niega lo que afirma. ¿Podrías señalar los versos y explicarlo?

Las imágenes de mujer, que los textos nos ofrecen, son múltiples y variadas. Si bien, en muchos poemas de épocas anteriores, las mujeres aparecen con frecuencia como objeto para la contemplación, como musa o amada, en los versos de Ugidos, Jodra y Díaz, que comentamos, la mujer es sujeto agente de su propia vida, se autoconstruye y diseña aceptando los titubeos, las vacilaciones, los errores; asume o rechaza lo heredado y edifica nuevas identidades.

En el "Poema de escarnio" de Silvia Ugidos encontramos que el objeto de contemplación, casi de disección, es el hombre. Es un texto que ofrece un punto de vista singular en el que un sujeto lírico femenino, desde la máscara que le proporciona la tradición literaria medieval de las coplas de maldecir, se dispone a realizar un retrato absolutamente corrosivo del varón. Son versos instalados en la contemporaneidad, en los que la mujer no se lamenta por el alejamiento de la pareja, sino que, por el contrario, se congratula por ello. Recurre, como hemos visto en otras ocasiones, a la intertextualidad, para conectar con un lector cómplice que complete el retrato. Así Ugidos actualiza, desde la perspectiva feminista, algunos ecos machadianos con los que bosqueja, entre la burla y la ironía, al hombre como objeto lírico. "Las mujeres conmigo siempre han sido crueles, / ¡si yo, como el poeta, de todas las arpías / amé cuanto ellas pueden tener de hospitalario!, dirá 
con gestos grandilocuentes y teatrales un sujeto masculino, que rebaja con sus propias palabras y sobreactuación el personaje, ya disminuido, que la mujer ha ido desvelando.

\section{Mirarse en el espejo. Escribir bajo consigna.}

Desde que en 1974 se fundara el primer taller de escritura, que luego sería conocido con el nombre de Grafein, han sido múltiples las propuestas de intervención didáctica en el aula por medio de actividades de creación literaria y talleres ${ }^{7}$ en los que la escritura bajo consigna ocupa un papel principal como técnica creativa: "La consigna es una fórmula breve que incita a la producción de un texto. Son un pretexto, una coartada, para comenzar a escribir, el punto de partida capaz de facilitar la creación de un nuevo texto" (Coto, 2002: 64). La eficacia de la consigna como impulsora de la producción textual ha sido puesta de relieve en múltiples ocasiones:

Escribir en el aula textos literarios a la manera de (al modo retórico, a partir de modelos expresivos de la tradición literaria, a partir de consignas, con mayor o menor libertad con respecto a las convenciones habituales, de forma individual o colectiva...) es una de las maneras más eficaces tanto a la hora de acercar a los alumnos y a las alumnas a la experiencia de la creación literaria como a la hora de estimular el uso poético y creativo del lenguaje. (Lomas, 1999: 114)

- Consigna $n^{0}$ 1: Escribe un autorretrato. Puedes usar la máscara autobiográfica. El tono puede ser serio, humorístico, irónico...

La consigna planteada propone a los estudiantes que escriban un autorretrato o un retrato. Los modelos propuestos son los analizados (textos 1, 2 y 3), así como el "Retrato" de Antonio Machado, que aparece como intertexto de "Posible autorretrato" (Silvia Ugidos).

7 De ellas hace un completo recuento Delmiro Coto (2002). Los talleres literarios como alternativa didáctica. En La escritura creativa en las aulas. En torno a los talleres literarios, (pp. 39-80). Barcelona: Graó. 
- Consigna $\mathrm{n}^{\circ}$ 2: Escribe un retrato que resalte los valores positivos de alguien y otro que destaque los negativos.

Naturalmente, no buscamos que el retrato se fundamente en ninguna persona real, eso deben saberlo los estudiantes, sino que pretendemos abordar la construcción del sujeto poético como una realidad textual. Con ello insistimos en el tema tratado en otras ocasiones que supone la insistencia en diferenciar entre el escritor o escritora y el sujeto poético que habla en el poema. El texto modelo es el "Poema de escarnio" de Silvia Ugidos.

\section{Conclusiones}

Estamos de acuerdo con la idea de que "la escritura creativa «enseña» a menudo más que grandes lecciones magistrales sobre el proceso que han seguido los grandes escritores para construir sus obras" (Bordons y Díaz-Plaja, 2006: 9). Por ello, nos parece que la intervención didáctica que proponemos puede apoyar el aumento de las competencias comunicativas y, en particular, el de la competencia literaria, sin olvidar que los textos, al ser muy ricos en recursos expresivos, nos permiten abordar el repaso de las figuras retóricas con la intención de que capten su funcionalidad en el texto y nunca como un repertorio de habilidades lingüísticas vacio de intención expresiva.

Porque entendemos, con Sánchez Corral (2003: 331), que "las prácticas con el lenguaje literario le brindarán a los alumnos la oportunidad de manifestarse contra la mediocridad, contra las visiones estereotipadas y contra el pensamiento único dominante en la sociedad actual", es por lo que proponemos este acercamiento didáctico a la escritura poética a partir de la lectura e interpretación de textos contemporáneos, en los que se someten a revisión estereotipos patriarcales y que, además, por su propia riqueza enunciativa, pueden servir de estímulo para la interpretación y la recreación de textos poéticos. 
Anexo. Textos

POSIBLE AUTORRETRATO.

Yo siempre quise ser una mujer de bien, ser alguien de provecho, valiente, emprendedora, mesurada en las fobias, estable en los afectos, brillante en los estudios, por poner un ejemplo.

Yo siempre quise ser una mujer de bien, $\mathrm{y}$ tenerlos a todos felices y contentos, a mis padres y amigos, a Fulano y Mengano, a Diestro y a Siniestro...

Pero hay alguien en mí que todo estropea, que tuerce los caminos, equivoca las cosas, desbarata mis planes, incumple mis promesas. Alguien que pisa antes que yo sobre mis huellas.

En fin, visto lo visto, ya lo dicen mis padres: "a este paso, hija mía, no llegarás a nada". Está bien, os lo debo, lo siento, lo confieso: aludiendo a un anuncio, no soy como Farala.

Soñadora, insegura, mitómana, algo vaga, con vocación de hormiga y verano de cigarra, contradictoria y harta de conciliar extremos. en mi defensa alego que siempre quise ser una mujer de bien, pero en su defecto soy, en el buen sentido de la palabra, mala.

(Silvia Ugidos, Las pruebas del delito, 1997) 


\begin{abstract}
V
Cuando una tiene sangre de ramera, brutal desprecio hacia la mayoría, tendencia a decir no a todo consejo e inclinación al mal por el mal mismo,

No podría ser casta aunque quisiera, integrarse en la masa no podría, y sin conseguir nada se hará viejo quien intente apartarla del abismo.

Pero además ocurre que ella no pondrá nada de su parte. ya tiene, y hace, y es, lo que prefiere; pensar siquiera en la virtud aburre a quien ha hecho del vicio todo un arte, y ni encuentra salida ni la quiere.
\end{abstract}

(Carmen Jodra, Las moras agraces, 1999)

\title{
DESDE EL ESPEJO
}

Siento una ligera sensación de vacío al mirarme al espejo. Mi tía abuela Asunción Martínez me dejó la memoria y cierta gracia para el recitado.

Mi abuela Agustina las artes culinarias y el crochet. Mi abuela Ana el miedo de caer por la escalera, o sea, el terror de morir como ella descalabrada en las losas de casa. De la hermana menor de mi padre la fobia por la tormenta y por

los pájaros.

Ni los ojos ni el asma en principio son míos.

Envejezco como mamá y en fin, en el espejo, pongo el aire.

Solo el aire que pasa.

(Rosa Díaz, Gata mamá, 2003) 


\section{POEMA DE ESCARNIO Y MALDECIR ${ }^{8}$}

[...] y para hacer balance haré un antología de aquellas cualidades que mejor te definen. Callaré los ejemplos sobre tu hipocondría, Otras enfermedades menos imaginarias son más ilustrativas sobre tu biografía. Destacabas en una con especial destreza: hacías todo un arte del aire victimista, una infancia terrible, conflictiva y oscura, un colegio de pago de moral jesuita, una madre muy viuda protectora en exceso y en cuestiones de faldas, muy poca puntería: Las mujeres conmigo siempre han sido crueles, isi yo, como el poeta, de todas las arpías amé cuanto ellas pueden tener de hospitalario!, forzando mucho el gesto solemne repetías. $\mathrm{Y}$ en cuanto a tus virtudes, tenías actitudes (no quisiera con esto darte alguna alegría) que hacían de ti un hombre de huella inolvidable; mencionaré tus celos, la obsesiva manía de que yo te engañaba, los interrogatorios, sesiones de Gestapo en las que me ofrecías tu propensión al circo (afectivo, se entiende), los gritos, las peleas, y tus frases dañinas, envenenados dardos que daban en el blanco creciente del cansancio que tú me producías. De tan triste inventario resumiré muy breve tu acoso interminable, tu vocación de espía, tus rastreros sobornos, tus trampas, tus enredos, amén de tus berrinches y tu voz compungida suplicando perdones, infinitos perdones cuando yo me cansaba de tantas tonterías y tus ramos de rosas para calmar las cosas. [...]

(Silvia Ugidos, Las pruebas del delito, 1997)

8 Solo reproducimos algunos fragmentos significativos. El poema puede leerse completo en Ugidos, S. Las pruebas del delito. 


\section{Referencias bibliográficas.}

Bajtín, M. (1975). Teoría y estética de la novela. Madrid: Taurus, 1989.

- (1979). Estética de la creación verbal. México: Siglo XXI, 1982.

Bordons, G. y Díaz-Plaja, A. (2006). Las aportaciones de la teoría de la literatura a la enseñanza, en Bordons y Díaz-Plaja (coords.) Enseñar literatura en secundaria. Barcelona: Graó.

Colomer, T. (1991). De la enseñanza de la literatura a la educación literaria. Comunicación, Lenguaje y Educación, 9,21-31. Barcelona: Ed. Fundación Infancia y Aprendizaje.

Delmiro Coto (2002). La escritura creativa en las aulas. En torno a los talleres literarios. Barcelona: Graó.

Jodra, C. (1999). Las moras agraces. Madrid: Hiperión.

López Valero A. (2000). El taller de creación como estrategia de iniciación literaria, en Llorens García, R. (ed.) Literatura infantil en la escuela, (pp. 36-54). Alicante: Universidad; Caja de Ahorros del Mediterráneo.

- (2003). Creación literaria y talleres, en Cerrillo Torremocha P. y Yubero Jiménez, S. (coords.), La formación de mediadores para la promoción de la lectura, (pp.123128). Cuenca: Universidad de Castilla-La Mancha, CEPLI.

- (2007). El taller de escritura creativa en la educación del siglo XXI, en Fernández Martínez, P. y Ahumada Fuentes, L. (Coords.) La magia de las letras: el desarrollo de la lectura y la escritura en la educación infantil y primaria, (pp. 43-66). Madrid: Ministerio de Educación.

Lomas, C. (1999). Cómo enseñar a hacer cosas con palabras II. Barcelona: Paidós.

Luna, L. (1996). Leyendo como mujer la imagen de la mujer. Barcelona: Anthropos.

Mendoza Fillola, A. (2001). El intertexto lector. El espacio de encuentro de las aportaciones del texto con las del lector. Cuenca: Ediciones de la Universidad de Castilla-La Mancha.

Rosal Nadales, M. (2006). Con voz propia. Estudio y antología comentada de la poesía escrita por mujeres (1970-2005). Sevilla: Renacimiento.

- (2008). ¿Qué cantan las poetas de ahora? Sevilla: Arcibel Editores.

- (2009). Matriherencia y matrofobia en la literatura española contemporánea, en Arriaga M. (dir.) Escrituras del sur, ( pp. 297-312). Sevilla: Arcibel Editores.

- (2009). Nuevas identidades femeninas: La ironía al servicio de la autoafirmación, en Lengua, Literatura y Género, X Simposio Internacional, 2007, pp. 679-696. Baeza: Universidad de Jaén, SEDLL.

Sánchez Corral, L. (2003). Didáctica de la literatura: relaciones entre el discurso y el sujeto, en A. Mendoza Fillola, Didáctica de la lengua y la literatura (Coord.)(pp. 319-348). Madrid: Pearson Educación.

- (2003). De la competencia literaria al proceso educativo: actividades y recursos, en A. Mendoza Fillola, Didáctica de la lengua y la literatura (Coord.), (pp. 319-348.) Madrid.

Servén, C. (2004). Educación para la igualdad y enseñanza de la literatura. Textos de Didáctica de la Lengua y la Literatura, 35. Barcelona: Graó. 
Creación poética y competencia literaria...

Ugidos, S. (1997). Las pruebas del delito. Barcelona: DVD.

(Artículo recibido: 30-09-2010; revisado: 27-11-2010; aceptado: 30-11-2010)

21 Álabe $\mathrm{n}^{\circ} 2$ - diciembre 2010 